\title{
Phylogenetic diversity of actinomycetes cultured from coastal multipond solar saltern in Tuticorin, India
}

\author{
Polpass Arul Jose and Solomon Robinson David Jebakumar ${ }^{*}$
}

\begin{abstract}
Background: Hypersaline solar salterns are extreme environments in many tropical and subtropical regions throughout the world. In India, there are several coastal solar salterns along with the coastal line of the Bay of Bengal and Arabian Sea and inland solar salterns around Sambhar saltlake, from which sodium chloride is obtained for human consumption and industrial needs. Studies on characterization of such coastal and inland solar salterns are scarce and both the bacterial and archaeal diversity of these extreme saline environment remains poorly understood. Moreover, there are no reports on exclusive diversity of actinomycetes inhabiting Indian solar salterns.

Results: Soil sediments were collected from both concentrator and crystallizer ponds of solar salterns and subjected to detailed physico-chemical analysis. Actinomycetes were selectively isolated by employing selective processing methods and agar media. A total of 12 representatives were selected from the 69 actinomycete isolates obtained from the saltern soil samples, using Amplified Ribosomal DNA Restriction Analysis. Sequencing and analysis of $16 \mathrm{~S}$ rDNA from chosen representative isolates displayed the presence of members affiliated to actinobacterial genera: Streptomyces, Micromonospora, Nocardia, Nocardiopsis, Saccharopolyspora and Nonomuraea. The genus Streptomyces was found to be the dominant among the isolates. Furthermore, rare actinomycete genus Nonomuraea was isolated for the first time from Indian solar salterns.

Conclusions: To the best of our knowledge, this study constitutes the first characterization of actinomycete diversity centred on solar salterns located in the eastern coastal region of India. Furthermore, this is the very first report of isolation of Nonomuraea species from solar salterns and also from India. As actinomycetes encompass recurrently foremost sources of biotechnologically important member of the microbial communities, the actinomycetes retrieved from the Indian saltern soil samples laid the platform to search for novel biotechnologically significant bioactive substances.
\end{abstract}

Keywords: Solar saltern, Actinomycete, ARDRA, Phylogeny, 16S rDNA, Nonomuraea

\section{Background}

Actinomycetes are outstanding collection of microorganisms with numerous affiliates reported for different kinds of bioactive features and extensive commercial importance $[1,2]$. Several reports on the ecology of actinomycetes have described that these microorganisms are widespread in nature and may occur in extreme environments. Accordingly, groups of acidophilic and alkaliphilic, psychrophilic and thermophilic, halophilic and

\footnotetext{
* Correspondence: jsolomon@mrna.tn.nic.in

Department of Molecular Microbiology, School of Biotechnology, Madurai Kamaraj University, Madurai 625 021, India
}

haloalkaliphilic, and xerophilic actinomycetes have been described $[3,4]$. The halophilic actinomycetes are noteworthy for their potential to produce bioactive compounds and enzymes [5,6]. In recent years, novel actinomycetes of diverse genera: Nocardiopsis, Saccharopolyspora, Myceligenerans and Streptomyces have been isolated from hypersaline environments [7-11]. Despite these findings, little is known about the diversity of actinomycetes in hypersaline environments. Search for novel and biotechnologically exploitable microorganisms has motivated researchers to screen largely unexplored extreme environments in which some chemical or physical factors differ considerably from that found in habitats
C Biomed Central

(c) 2012 Arul Jose and Jebakumar; licensee BioMed Central Ltd. This is an Open Access article distributed under the terms of the Creative Commons Attribution License (http://creativecommons.org/licenses/by/2.0), which permits unrestricted use, distribution, and reproduction in any medium, provided the original work is properly cited. 
which support human life. Moreover, the exploration of untapped actinomycetes diversity is a key practice for hunting novel taxa and genes of value to biotechnology [12,13].

The solar salterns are hypersaline environments that consist of a series of shallow ponds connected in a sequence of increasing saline brines that are used for the commercial production of salt from seawater [14]. Sequential precipitation of calcium carbonate, calcium sulfate and sodium chloride occurs during the evaporation of seawater. India is the third largest salt producing country in the world with an extent of about 5.50 lakh acres engaged in salt production. The coastal solar salterns accounts for about $91 \%$ of the country's salt production and inland salterns accounts for remaining $9 \%$ of production. There have been several investigations on microbial assemblages in such hypersaline solar salterns $[15,16]$. The diversity of these microbial assemblages in hypersaline environments has been studied by employing both molecular and culture-dependent methods [17-20]. Previous studies of Indian solar salterns have been focused on the archeal [21] and Cyanobacterial [22] diversity. The aims of the present work were to use selective processing methods to isolate actinomycetes from coastal solar saltern ponds and to determine their phylogenetic diversity.

\section{Results}

\section{Physico-chemical characteristics of saltern soil}

The physico-chemical characteristics of soil samples collected from both concentrator and crystallizer ponds of

Table 1 Physico-chemical parameters observed in the soil samples collected from both Concentrator and Crystallizer ponds of coastal solar saltern

\begin{tabular}{lll}
\hline Parameters & \multicolumn{2}{l}{ Values $(\mathbf{p p m})^{*}$} \\
\cline { 2 - 3 } & Concentrator Pond & Crystallizer Pond \\
\hline $\mathrm{pH}^{*}$ & 8.15 & 8.27 \\
$\mathrm{EC}(\mathrm{dSm}-1)^{*}$ & 12.75 & 12.92 \\
T. Sodium & 3340 & 3840 \\
T. Nitrogen & 140 & 130 \\
T. Phosphorus & 240 & 240 \\
T. Potassium & 460 & 460 \\
Organic C & 1500 & 1200 \\
Fe & 35.44 & 28.88 \\
Mn & 11.16 & 15.44 \\
$\mathrm{Zn}$ & 23.8 & 4.44 \\
$\mathrm{Cu}$ & 1.5 & 1.3 \\
\hline
\end{tabular}

*Values are in ppm except for $\mathrm{pH}$ and EC. solar salterns at Tuticorin, India were studied using standard protocols and summarized in Table 1. Several parameters, such as $\mathrm{pH}$, electric conductivity, concentration of macroelements and trace elements were measured. The $\mathrm{pH}$ was just above neutral in both concentrator and crystallizer ponds and negligible variation was found between the ponds. Likewise, the EC values of concentrator and crystallizer pond soil samples were found to be 12.75 and 12.92, respectively. This moderate EC values conforms the hypersaline nature of both soil samples. Sodium and potassium were found to be dominant in both ponds.

\section{Selective isolation of actinomycetes}

A total of 69 actinomycete isolates were obtained from saltpan soil samples using two sample processing methods and four different isolation media. Among the two sample-processing methods, stamping dried sediments onto low-nutrient agar (IM4) resulted in the isolation of $68 \%$ of actinomycete strains which proved to be a highly successful method to cultivate actinomycete and the result is in accordance with the earlier report of Gontang et al. [23].

\section{5 rDNA amplification and ARDRA}

PCR amplification of 16S rDNA using a set of universal eubacterial specific primers: $27 \mathrm{~F}$ and $1492 \mathrm{R}$ yielded a single amplicon of $\sim 1500 \mathrm{bp}$ for all the isolates. Restriction digestion of these amplicons with HaeIII yielded different profiles characterized by three to four fragments ranging from $100 \mathrm{bp}$ to $700 \mathrm{bp}$ in size for the different isolates. When amplicons were digested with restriction enzyme TaqI, almost similar profile was obtained for all the isolates. The actinomycete isolates were divided into of 12 groups in a dendrogram (Figure 1) inferred from ARDRA patterns obtained with HaeIII. Group I has 7 isolates, Groups VII, IX and XII have 3 isolates each. The groups II, XI, VII, IV, VI and $\mathrm{X}$ have 10, 2, 8, 5, 6 and 9 isolates, respectively.

\section{Actinomycete community composition and phylogenetic analysis \\ 16S rDNA of 12 representative isolates belonging to differ- ent clusters established by ARDRA was sequenced and used to determine the diversity among the isolates. These representatives were affiliated with one of the following five genera belonging to Actinobacteria (Figure 2).}

\section{Streptomyces}

The most abundant group of isolates was affiliated with the genus Streptomyces, represented by six ribotypes accounting for $48 \%$ of the total actinomycete population. Of these ribotypes JAJ07 and JAJ13 fell in a same clade in 


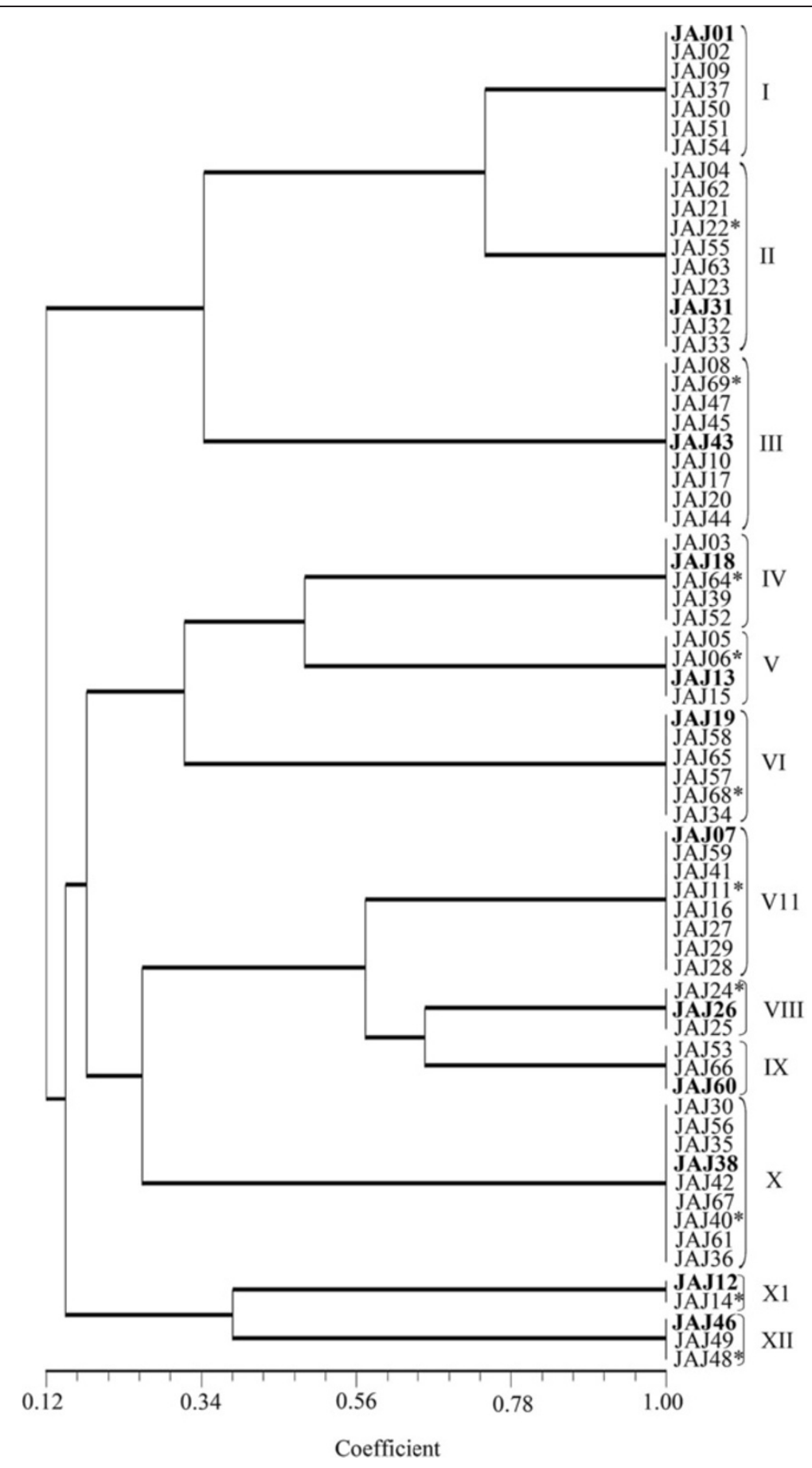

Figure 1 UPGMA dendrogram inferred from ARDRA patterns of actinomycetes isolated from solar saltern ponds. The dendrogram shows the clustering of 69 actinomycete isolates generated from amplified ribosomal DNA restriction analysis with restriction endonuclease Haelll, using the UPGMA algorithm and the Jaccard's coefficient. The Roman numerals I to XII represent the twelve clusters obtained in the analysis. The ribotypes selected from sequencing analysis are highlighted in boldface. The additional isolates subjected to sequence analysis are starred.

the phylogenetic tree with $99 \%$ and $98 \%$ sequence similarities respectively to nearest type strain Streptomyces radiopugnans (GenBank: DQ912930), representing 18\% of total isolates. The other ribotypes of Streptomyces, JAJ19 (GenBank: JN859006) (representing 9\% of isolates) and JAJ26 (GenBank: JN859004) (representing 4\% of 


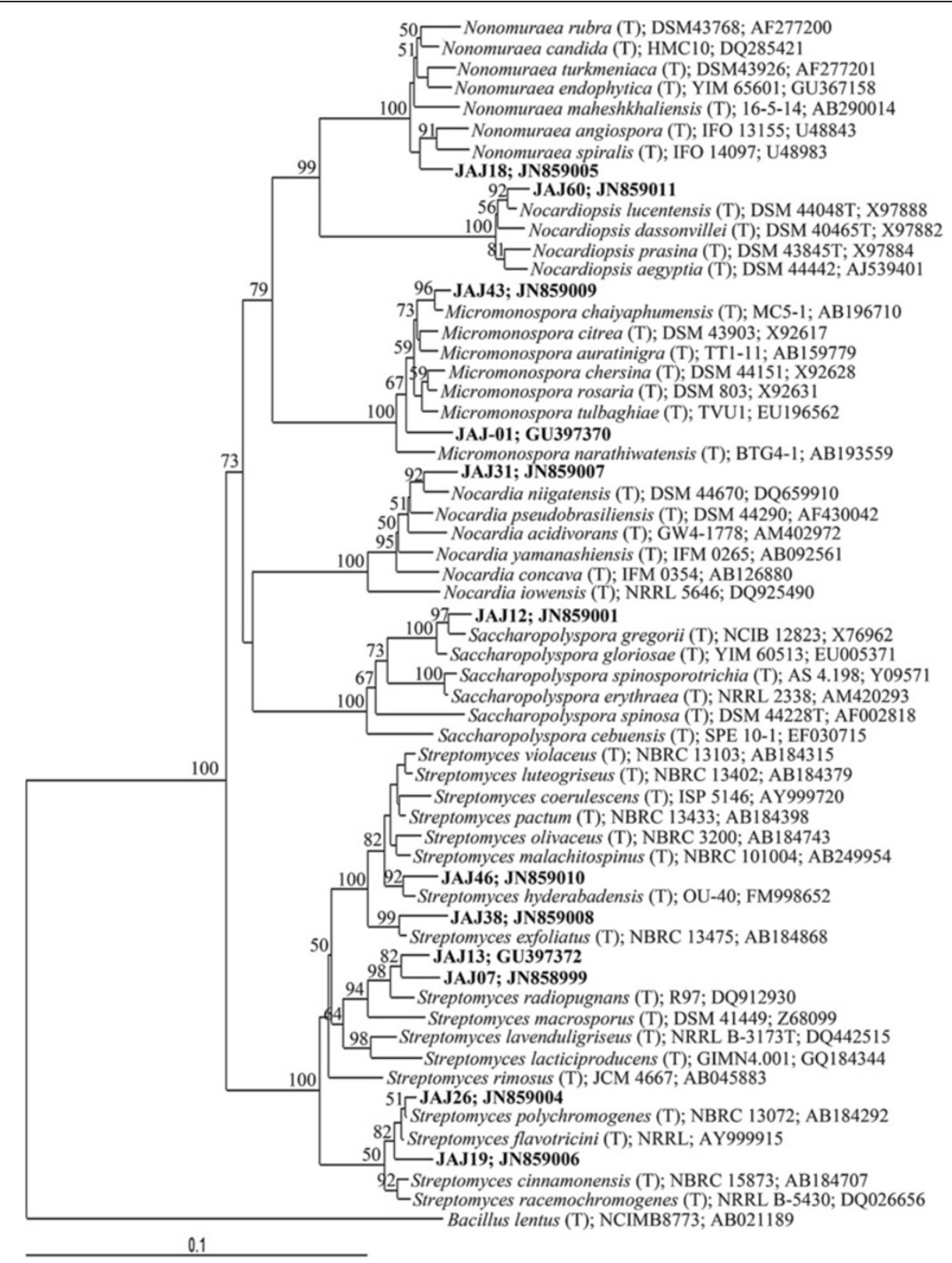

Figure 2 Neighbour-joining phylogenetic tree inferred from 16S rRNA gene sequences. The phylogenetic tree shows the phylogenetic relationship of isolates with related genera. Bootstrap values are expressed as percentages of 1000 replications. Bootstrap values, $>50 \%$ are shown at branch points. Bacillus lentus ${ }^{\top}$ (GenBank accession number AB021189) was used as out-group. Score bar represents 1 nucleotide substitution per 100 nucleotides.

all isolates) were closely related to type strain Streptomyces flavotricini (GenBank: AY999915) with 99.9\% sequence similarity and Streptomyces polychromogenes (GenBank: AB184292) with 99.9\% sequence similarity, respectively. The ribotype JAJ46 (GenBank: JN859010) was clustered with Streptomyces hyderabadensis (GenBank: FM998652) with $98 \%$ of sequence identity, representing $4 \%$ of all actinomycete isolates. Likewise, the ribotype JAJ38
(GenBank: JN859008) was clustered with Streptomyces exfoliatus (GenBank: AB184868) by $99.5 \%$ sequence identity, representing $13 \%$ of all isolates.

\section{Micromonospora}

The second most dominant group in the isolates was the genera Micromonospora, represented by two different ribotypes accounting for $23 \%$ of total actinomycete 
isolates. Ribotype JAJ43 (GenBank: JN859009) was 99\% identical to type strain Micromonospora chaiyaphumensis (GenBank: AB196710), representing 13\% of the entire actinomycete population. Ribotype JAJ01 (GenBank: GU397370) was related to type strain Micromonospora tulbaghiae (GenBank: EU196562) with 99\% sequence similarity, representing $10 \%$ of all actinomycetes isolates.

\section{Nocardia}

This genus was represented by ribotype JAJ31 (GenBank: JN859007), representing 15\% of all actinomycete isolates, showed $98 \%$ sequence similarity to type strain Nocardia niigatensis (GenBank: DQ659910).

\section{Nonomuraea}

The ribotype JAJ18 (GenBank: JN859005) was clustered with type strains Nonomuraea spiralis (GenBank: U48983, 98.5\% 16S rDNA sequence identity) and Nonomuraea angiospora GenBank: (U48843, 98\% 16S rDNA sequence identity), representing $7 \%$ of all actinomycete isolates.

\section{Nocardiopsis}

The genus Nocardiopsis was also represented by only one phylotype. The ribotype JAJ60 (GenBank: JN859011), representing $4 \%$ of all actinomycete isolates, shared $99 \%$ sequence similarity with type strain Nocardiopsis lucentensis (GenBank: X97888).

\section{Saccharopolyspora}

The ribotype JAJ12 (GenBank: JN859001) was identified as Saccharopolyspora species, representing 3\% of all actinomycete isolates, showed $99 \%$ sequence similarity to type strain Saccharopolyspora gregorii (GenBank: X76962).

\section{Morphology of actinomycete isolates}

Morphology of representative isolates was visually observed and their aerial and substrate mycelium are shown in Figure 3. The isolates JAJ13, JAJ07, JAJ19, JAJ26, JAJ38 and JAJ46 grew well on IM2 with characteristic musty odour, spore formation, dimorphic mycelial forms as aerial and subterranean mycelium and non-motile colonies. All these streptomycete isolates attained maximum growth with grey to white coloured sporulation after three days of incubation. Isolates JAJ01 and JAJ43, lacking aerial mycelium on IM2, grew with pigmentation that ranged from bright to pale orange to black and pale to golden yellow colour respectively.

Isolate JAJ18 which was identified as Nonomuraea species, produced disc shaped pink colour colonies with sporulation largely at the edges of the colony. Isolate JAJ31, identified as Nocardia species, produced cream color aerial mycelium and wheat colour substrate mycelium. Saccharopolyspora strain, JAJ12 produced snow white aerial mycelium and wheat colour substrate mycelium. Isolate JAJ60, identified as Nocardiopsis species produced grey aerial mycelium and substrate mycelium with moderate sporulation on IM2.

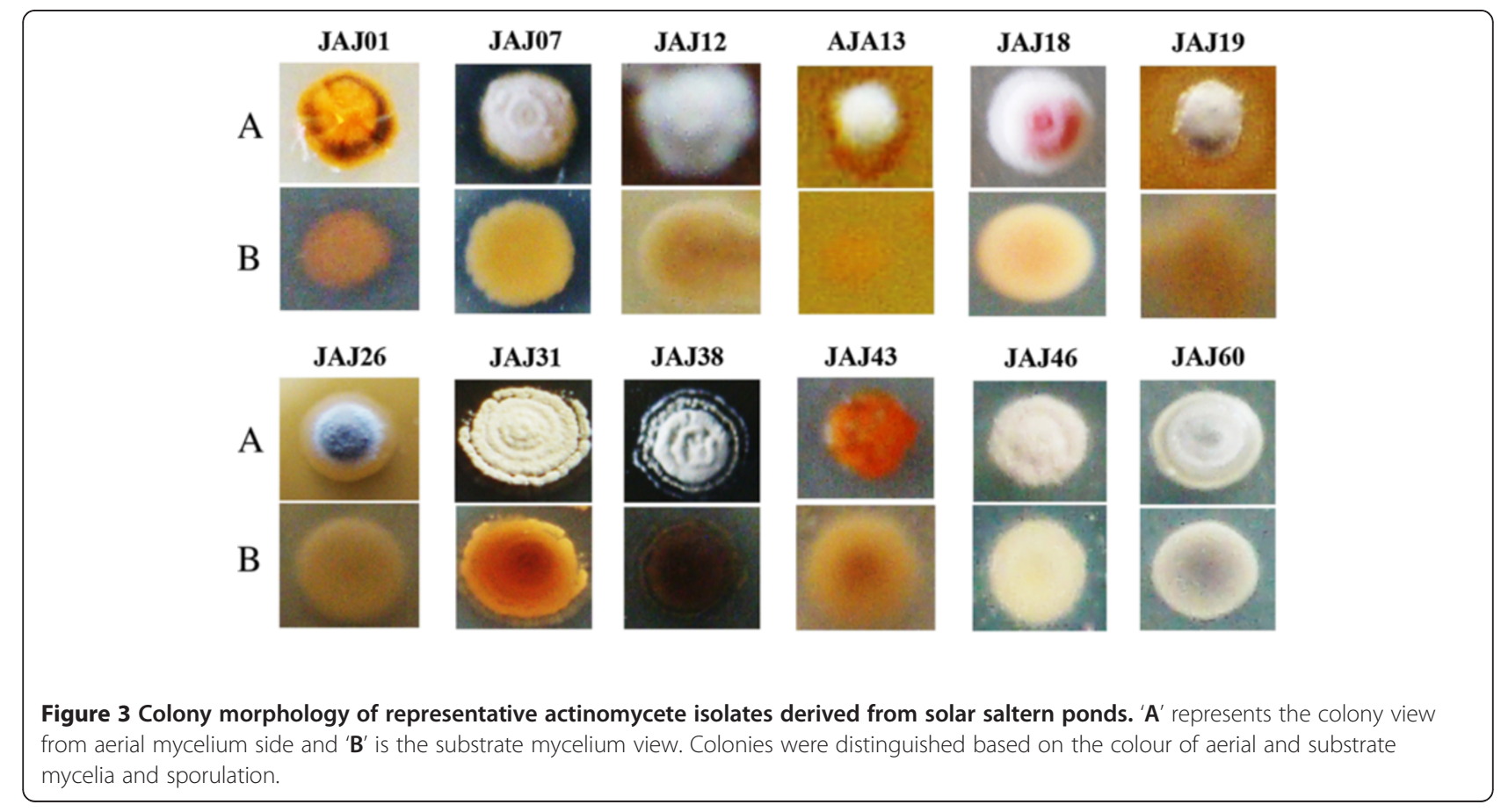




\section{Discussion}

Hypersaline multi-pond solar salterns are renowned as a habitat for halophiles $[15-17,19,20]$ and an understanding of the microbial assemblages in such hypersaline environments is highly desirable due to their potential applications $[5,6,11]$. In this study, selective isolation techniques employing heat treatment and stamping have been used to assess actinomycetes population in soil sediments from the solar salterns. The role of selective isolation procedures is often vital for isolation of rare and novel actinomycetes [23,24]. A combination of stamping method and low nutrient agar medium was described as efficient method for the isolation of novel actinomycetes from marine sediments [23]. Among the 69 isolates, most of the isolates including Nonomuraea and Micromonospora were obtained from low nutrient IM4 plates stamped with dried samples, even though sediment-processing methods were not applied equally to all samples. The low nutrient medium slowed down the growth of fast growing Gram negative bacteria and the stamping favoured the germination of actinomycete spores adhered to soil particles. The antibiotics used with agar medium also favoured the growth of actinomycetes by preventing the growth of fungal strains and other contaminants. In a nutshell, the selective isolation methods favoured the isolation of variety of actinomycetes inclusive of Nonomuraea species from the solar saltern.

The microbial phylogenetic diversity among the isolated actinomycetes was studied based on their $16 \mathrm{~S}$ rDNA. ARDRA was employed in this study to assist in distinguishing among the taxonomic groups. The ARDRA is an extension of RFLP technique, commits the four cutter restriction enzymes to discriminate the microbes at inter genus and intra genus levels [25-28]. The restriction enzyme, HaeIII recognizes specific tetranucleotide sites available frequently in DNA, widely used for discrimination of bacterial species $[29,30]$. In the present study, twelve actinomycete isolates were selected as representative strains from the entire actinomycete population using ARDRA with HaeIII. The 16S rDNA sequence data of isolates other than the selected representatives revealed that some different species of same genus showed same ARDRA pattern but species of different genus did not show the same ARDRA pattern and it conformed the coverage of all genera encompassed by the entire actinomycetes population, even though all the species were not covered. In other words the ARDRA performed with HaeIII successively have discriminated the isolates at genus level and only to some extent the species level.

Phylogenetic analysis based on 16S rRNA gene sequences of representative isolates revealed the presence of actinomycetes affiliated to five genera; Streptomyces,
Micromonospora, Nocardia, Nonomuraea, Saccharopolyspora, and Nocardiopsis in saltern soil samples. The most abundant actinomycete group detected was allocated to the genus Streptomyces followed by Micromonospora. The predominance of the Streptomyces followed by Micromonospora has already been observed previously in saline soils [31]. The Nocardia accomplish the third position of predominance among the all actinomycete isolates. Occurrence of Nocardia in hypersaline environment has previously been reported by Quesada et al. [32]

Existence of Nonomuraea, Saccharopolyspora and Nocardiopsis were also found in the saltern ponds. Previously the genus Nonomuraea has been reported from various soil samples including arid soil, cave soil and mangrove rhizosphere [33-35]. However, there are no reports on isolation of Nonomuraea species from saline lakes or solar saltern ponds and also from India. The other two genera, Saccharopolyspora and Nocardiopsis have frequently been isolated from salt lakes and saline soils $[36,37]$.

\section{Conclusion}

In this study, actinomycete diversity was explored from the Indian coastal solar salterns and the isolates recovered were assigned to five genera on the basis of their $16 \mathrm{~S}$ rDNA sequences and this is the first step towards better understanding of actinomycete community from solar saltern ponds in Tuticorin, India. In a nutshell, the results obtained reveal the significant actinomycete diversity and further researches including the bioactive assays and molecular characterizations are needed to clarify the biotechnological importance and ecological roles of this actinomycete population.

\section{Methods}

\section{Sample collection and physico-chemical analysis}

Saltpan sediment samples were collected aseptically from two different salinity ponds: concentrator ponds and crystallizer ponds of solar salterns from Tuticorin (about Latitude $8.43 \mathrm{~N}$ and Longitude 78.60E) in India (Figure 4). The collected samples were subjected to physiochemical analysis following standard methods. Soil $\mathrm{pH}$ and electrical conductivity (EC) were measured using a soil/water suspension $(1: 2 \mathrm{w} / \mathrm{v})$ with potentiometer and conductimeter respectively according to Jackson [38]. The saltpan mud soil sample was air dried and organic matter [organic carbon] was determined according to the method of Walkley and Black [39]. Total nitrogen was determined by the micro kjeldahl method [38]. Total Phosphorous was estimated according to Pemberton [40]. Total sodium and potassium was estimated using atomic absorption spectrophotometer (AA-6200, Shimadzu, Japan). The total nitrogen, phosphorus and potassium estimations were carried out after the acid 


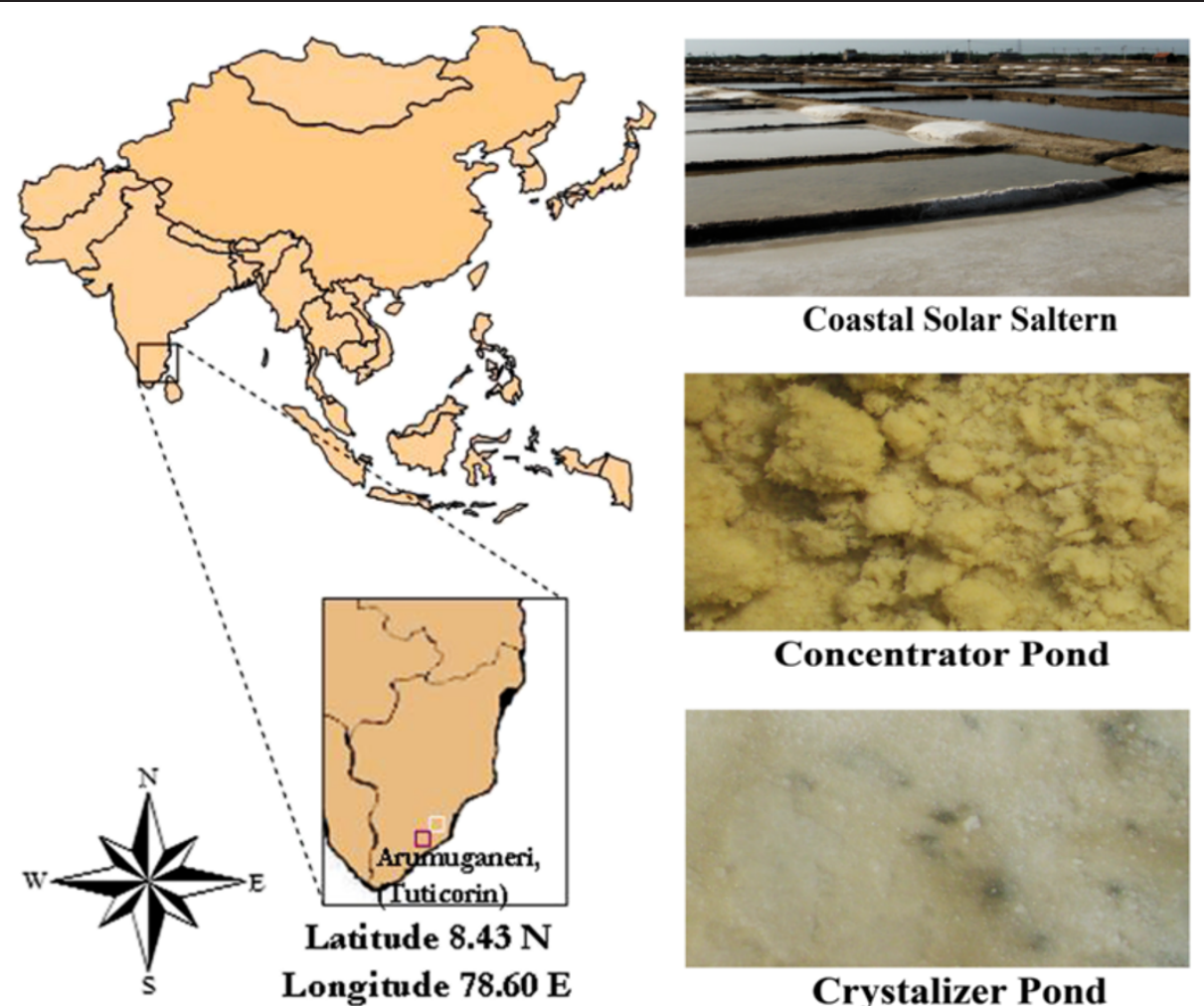

Figure 4 Map of the location of the sampling site and appearance of coastal solar saltern ponds. Tuticorin is one of the major salt production sites in India. Soil samples were collected from both the concentrator pond and crystallizer pond of the solar saltern for this work.

digestion of soil samples. Micronutrients, $\mathrm{Zn}, \mathrm{Cu}, \mathrm{Fe}$ and Mn were determined using flame photometry.

\section{Sample processing and selective isolation}

Ten composite samples were made from five samples collected randomly from each pond of the solar saltern. The composite samples were homogenized and portions processed by one or another of the following two selective methods modified from the earlier methods described by Gontang et al. [23] to reduce the numbers of Gramnegative bacteria and to enrich slow-growing, sporeforming actinomycetes. In the first processing method, $10 \mathrm{~g}$ of wet sediment sample was dried overnight in a laminar flow hood, ground lightly with a sterile pestle and stamped onto the agar media using sterile cotton plug, creating a serial dilution effect. In the second processing method (dilution-and-heat-shock method), 1 gm of the sample was suspended in $4 \mathrm{ml}$ of sterile water, heated for $6 \mathrm{~min}$ at $55^{\circ} \mathrm{C}$, vigorously shaken and further diluted (1:4) in sterile water, and $50 \mu \mathrm{l}$ of each dilution was spread with a sterile glass rod onto agar-based isolation media.

Isolation media contained the following components: IM1[41], $10 \mathrm{~g}$ of starch, $4 \mathrm{~g}$ of yeast extract, $2 \mathrm{~g}$ of peptone,
$18 \mathrm{~g}$ of agar, and 1 liter of natural seawater; IM2 [11], $10 \mathrm{~g}$ of starch, $4 \mathrm{~g}$ of yeast extract, $5 \mathrm{~g}$ of $\mathrm{NaCl}, 2 \mathrm{~g}$ of $\mathrm{NH}_{4} \mathrm{SO}_{4}$, $1 \mathrm{~g}$ of $\mathrm{MgSO}_{4}, 1 \mathrm{~g}$ of $\mathrm{K}_{2} \mathrm{HPO}_{4}, 22 \mathrm{~g}$ of agar, and 1 liter of distilled water; IM3 (Starch Casein Salt Agar) [42], $10 \mathrm{~g}$ of Starch, $0.3 \mathrm{~g}$ of casein, $2 \mathrm{~g}$ of $\mathrm{KNO}_{3}, 4.6 \mathrm{~g}$ of sodium chloride, $2 \mathrm{~g}$ of $\mathrm{K}_{2} \mathrm{HPO}_{4}, 0.05 \mathrm{~g}$ of $\mathrm{MgSO}_{4}, 0.02 \mathrm{~g}$ of $\mathrm{CaCO}_{3}$, $0.01 \mathrm{~g}$ of $\mathrm{FeSO}_{4}, 1 \mathrm{mg}$ of $\mathrm{Zn}\left(\mathrm{O}_{2} \mathrm{CCH}_{3}\right)_{2}, 18 \mathrm{~g}$ of agar and 1 litre of distilled water; and IM4 [41], $6 \mathrm{~g}$ of glucose, $2 \mathrm{~g}$ of chitin, $18 \mathrm{~g}$ of agar, and 1 liter of natural seawater. All isolation media were amended with filter-sterilized cycloheximide $(100 \mu \mathrm{g} / \mathrm{ml})$ and nalidixic acid $(5 \mu \mathrm{g} / \mathrm{ml})$ to favor the selective isolation of actinomycetes. Inoculated plates were incubated at $30^{\circ} \mathrm{C}$ for up to 6 weeks, and all leathery colonies were removed from the original isolation plates and sub-cultured on IM2.

\section{S rDNA amplification}

Isolates were grown in trypticase soy broth supplemented with $1-2 \% \mathrm{NaCl}[\mathrm{w} / \mathrm{v}]$ or NDYE medium according to their growth in $150 \mathrm{ml}$ conical flasks for 3-5 d. The mycelia were harvested from the broth by centrifugation at 10,000 rpm for $3 \mathrm{~min}$ and washed twice with sterile milli Q water. From the harvested mycelia, the DNA 
was extracted following standard phenol-chloroform extraction procedure [43].

The $16 \mathrm{~S}$ rDNA was amplified from genomic DNA samples using eubacterial universal primers $27 \mathrm{~F} 5^{\prime}$ AGAGTT TGA TCC TGG CTC AG-3' and 1492R 5'GGT TAC CTT GTT ACG ACT T-3' [44]. The amplification was carried out in a $50 \mu \mathrm{L}$ volume by using $25 \mathrm{ng}$ of genomic DNA as template with $1 \mathrm{X}$ reaction Buffer (10 mM Tris pH 8.3, $50 \mathrm{mM} \mathrm{KCl,} 1.5 \mathrm{mM} \mathrm{MgCl}_{2}$ ), $200 \mu \mathrm{M}$ of each dNTP, $10 \mathrm{pM}$ of each primer and 0.05 $\mathrm{U}$ of Taq DNA polymerase (Sigma, USA). The thermal cycling conditions were as follows: initial denaturation at $94^{\circ} \mathrm{C}$ for $5 \mathrm{~min} ; 31$ cycles at $95^{\circ} \mathrm{C}$ for $30 \mathrm{~s}, 54^{\circ} \mathrm{C}$ for $90 \mathrm{~s}$ and $72^{\circ} \mathrm{C}$ for $120 \mathrm{~s}$; and a final extension at $72^{\circ} \mathrm{C}$ for $5 \mathrm{~min}$. The amplification reaction was performed by Bio-Rad thermal cycler (MyCycler, Bio-Rad, USA) and the amplified products were examined by $1 \%$ agarose gel electrophoresis.

\section{Amplified ribosomal DNA restriction analysis (ARDRA)}

To identify the number of polymorphic groups and select representative strains among the actinomycete isolates, aliquots of purified 16S rDNA amplicons were subjected to amplified ribosomal DNA restriction analysis. The purified PCR products were digested separately with HaeIII and $\operatorname{Hinf} \mathrm{I}$, in $20 \mu \mathrm{L}$ reaction volume by using manufacture's recommended buffer and temperature. The digested restriction fragments were electrophoresed in $2.5 \%$ agarose gels using TE buffer. The gels were stained with ethidium bromide and visualized under UV transilluminator. Strong and clear bands were scored in a binary data form and used for similarity and clustering analysis in numerical taxonomy analysis program package, NTSYS-pc 2.02i [45]. Similarities among the isolates were calculated by Jaccard's coefficient [46] and the dendrogram was constructed using UPGMA method [47].

\section{S rDNA sequencing and phylogenetic analysis}

The PCR amplicons of 12 actinomycete isolates with representative ARDRA profiles were purified using PCR product purification spin kit (HiPurA, HiMedia, India) and sequenced by Applied Biosystems 3730XL DNA Analyzer using same primer set as used in PCR amplification. In addition to chosen representative isolates, $16 \mathrm{~S}$ rDNA of 10 other actinomycete isolates that showed ARDRA patterns identical to representative isolates were also sequenced to validate the ARDRA. All the sequences obtained from sequencing were analyzed and edited by using BioEdit software [48]. Initially all the $16 \mathrm{~S}$ rRNA sequences were compared to sequences in GenBank by use of the Basic Local Alignment Search Tool online service to determine approximate phylogenetic position [49]. Sequences then were aligned using ClustalX [50] with representative actinomycete16S rRNA gene sequences. Phylogenetic tree was inferred by using suitable programs of the PHYLIP (phylogeny inference package) version 3.68 [51].

\section{Morphology of representative strains}

All the representative isolates obtained from ARDRA analysis were subjected to morphological characterization on IM2. Inoculated plates were incubated at $29^{\circ} \mathrm{C}$ for 7 to 10 days and their morphology was visually observed.

\section{Nucleotide sequence accession numbers}

The 16S rRNA gene sequences of representative strains have been deposited in the GenBank database under the accession numbers GenBank: JN858999 - GenBank: N859013 and GenBank: GU397370 - GenBank: GU397372.

\section{Competing interests}

Both authors declare that they have no competing interests.

\section{Authors' contributions}

PAJ and Prof. Solomon collected samples from Tuticorin, India on $23^{\text {rd }}$ March 2010. PAJ carried out all the experiments, analyzed data, and drafted the manuscript under the complete guidance of Prof. Solomon. Both the authors read and approved the final manuscript.

\section{Acknowledgements}

PAJ is grateful for the funding from 'Research Fellowship in Science for Meritorious Students Scheme' of University Grant Commission, India. We are also thankful to the UGC-UPE Project, Madurai Kamaraj University for accessing the funded resource facilities in our laboratory.

Received: 22 May 2012 Accepted: 7 August 2012

Published: 5 September 2012

\section{References}

1. Raja A, Prabakarana P: Actinomycetes and drug-an overview. Am J Drug Discovery Dev 2011, 1:75-84.

2. Kurtböke Dl: Biodiscovery from microbial resources: actinomycetes leading the way. Microbiol Aust 2010, 31:53-57.

3. Jiang C, Xu L: Actinomycete diversity in unusual habitats. Actinomycetes 1993, 4:47-57.1993.

4. Selianin W, Oborotov GE, Zenova GM, Zvyagintsev DG: Alkaliphilic soil actinomycetes. Mikrobiologiia 2005, 74:838-844.

5. Mohamed SH, Galal AM: Identification and antiviral activities of some halotolerant Streptomycetes isolated from Qaroon Lake. Int J of Agri biol 2005, 7:747-753.

6. Gurielidze M, Pataraya D, Cholokava N, Nutsubidze N: Extremophilic Actinomycetes, distributed in various types of soils of Georgia and their protease activity. Bull Georg Natl Acad Sci 2010, 4:81-85.

7. Al-Tai AM, Ruan J-S: Nocardiopsis halophila sp. nov., a new halophilic actinomycete isolated from soi. Int J Syst Bacteriol 1994, 44:474-478.

8. Chen Y-G, Cui X-L, Kroppenstedt RM, Stackebrandt E, Wen M-L, Xu L-H, Jiang C-L: Nocardiopsis quinghaiensis sp. nov., isolated from saline soil in China. Int J Syst Evol Microbiol 2008, 58:699-705.

9. Guan T-W, Wu N, Xia Z-F, Ruan J-S, Zhang XP: Saccharopolyspora lacisalsi sp. nov., a novel halophilic actinomycete isolated from a salt lake in Xinjiang, China. Extremophiles 2011, 15:373-378.

10. Wang Y, Tang SK, Li Z, Lou K, Mao PH, Jin X, Klenk HP, Zhang LX, Li WJ: Myceligenerans halotolerans sp. nov., an actinomycete isolated from a salt lake, and emended description of the genus Myceligenerans. Int J Syst Evol Microbiol 2011, 61:974-978.

11. Jose PA, Santhi VS, Jebakumar SRD: Phylogenetic-affiliation, antimicrobial potential and PKS gene sequence analysis of moderately halophilic Streptomyces sp. inhabiting an Indian saltpan. J Basic Microbiol 2011, 51:348-356.

12. Nolan RD, Cross T: Isolation and screening of actinomycetes. In Actinomycetes in biotechnology. Edited by Goodfellow M, Williams ST, Mordarski M. San Diego, CA: Academic Press, Inc; 1988. 
13. Genilloud O, González I, Salazar O, Martín J, Tormo JR, Vicente F: Current approaches to exploit actinomycetes as a source of novel natural products. J Ind Microbiol Biotechnol 2011, 38:375-389.

14. Diez B, Antón J, Guixa-Boixereu N, Pedrós-Alió C, Rodriguez-Valera F: Pulsed-field gel electrophoresis analysis of virus assemblages present in a hypersaline environment. Int Microbiol 2000, 3:159-164.

15. Benlloch S, Acinas SG, Anton J, Lopez-Lopez A, Luz SP, Rodriguez-Valera F: Archaeal biodiversity in crystallizer ponds from a solar saltern: culture versus PCR. Microb Ecol 2001, 41:12-19.

16. Baati H, Guermazi $S$, Amdouni R, Gharsallah N, Sghir A, Ammar E: Prokaryotic diversity of a Tunisian multipond solar saltern. Extremophiles 2008, 4:505-518.

17. Burns DG, Camakaris HM, Janssen PH, Dyall-Smith ML: Combined use of cultivation-dependent and cultivation-independent methods indicate that members of most haloarchaeal groups in an Australian crystallizer pond are cultivable. Appl Environ Microbiol 2004, 70:5258-5265.

18. Ovreas L, Daae FL, Torsvik V, Rodriguez-Valera F: Characterization of microbial diversity in hypersaline environments by melting profiles and reassociation kinetics in combination with terminal restriction fragment length polymorphism [T-RFLP]. Microb Ecol 2003, 46:291-301.

19. Ghai $R$, Pašić L, Fernández AB, Martin-Cuadrado A, Mizuno CM, McMahon KD, Papke RT R, Stepanauskas R, Rodriguez-Brito B, Rohwer F, Sánchez-Porro C, Ventosa A, Rodríguez-Valera F: New abundant microbial groups in aquatic hypersaline environments. Sci Rep 2011, 1:135.

20. Narasingarao P, Podell S, Ugalde JA, Brochier-Armanet C, Emerson JB, Brocks $\mathrm{JJ}$, Heidelberg KB, Banfield JF, Allen EE: De novo metagenomic assembly reveals abundant novel major lineage of Archaea in hypersaline microbial communities. ISME J 2012, 6:81-93.

21. Ahmad N, Johri S, Sultan P, Abdin MZ, Qazi GN: Phylogenetic characterization of Archaea in Saltpan sediments. Indian J Microbiol 2008, 51:132-137.

22. Nagasathya A, Thajuddin N: Cyanobacterial diversity in the hypersaline environment of the saltpans of Southern coast of India. Asian J Plant SCi 2008, 7:473-478.

23. Gontang EA, Fenical W, Jensen PR: Phylogenetic diversity of gram-positive bacteria cultured from marine sediments. Appl environ microbiol 2007, 73:3272-3282

24. Hayakawa M, Momose Y, Kajiura T, Yamajaki T, Tamura T, Hatano K, Nonomura $\mathrm{H}$ : A selective isolation method for Actinomadura viridis in soil. J Ferment Biogin 1995, 1995(79):287-289.

25. Wilson RW, Steingrube VA, Brown BA, Wallace RJ Jr: Clinical application of PCR-restriction enzyme pattern analysis for rapid identification of aerobic actinomycete Isolates. J Clinical Microbiol 1998, 36:148-152.

26. Cook AE, Meyers PR: Rapid identification of filamentous actinomycetes to the genus level using genus-specific 16S rRNA gene restriction fragment patterns. Int J Syst Evol Microbiol 2003, 53:1907-1915.

27. Satheeja SV, Jebakumar SRD: Phylogenetic analysis and antimicrobial activities of Streptomyces isolates from mangrove sediment. J. Basic Microbiol 2011, 51:71-79.

28. Sasaki H, Kawamoto E, Okiyama E, Ueshiba H, Mikazuki K, Amao H, Sawada T: Molecular typing of Pasteurella pneumotropica isolated from rodents by amplified $16 \mathrm{~S}$ ribosomal DNA restriction analysis and pulsed-field gel electrophoresis. Microbiol Immunol 2006, 50:265-272.

29. Soto LP, Frizzo LS, Bertozzi E, Avataneo E, Sequeira GJ, Rosmini MR: Molecular microbial analysis of lactobacillus strains isolated from the gut of calves for potential probiotic use. Vet Med Int 2010, 201:274987.

30. Ingrassia T, Roques C, Prevots F: Preliminary experiments for ARDRA validation on flora associated with intestinal mucosa. Lait 2001, 81:263-280

31. Zvyagintsev DG, Zenova GM, Oborotov GV: Mycelial bacteria of saline soils. Eurasian Soil Sci 2008, 41:1107-1114.

32. Quesada E, Ventosa A, Rodriguez-Valera F, Ramos-Cormenzana A: Types and properties of some bacteria isolated from hypersaline soils. J Appl Microbiol 1982, 53:155-161.

33. Camas M, Sazak A, Spröer C, Klenk HP, Cetin D, Guven K, Sahin N: Nonomuraea jabiensis sp. nov., isolated from Nigerian arid soil. Int J Syst Evol Microbiol 2012, doi:10.1099/ijs.0.039362-0.
34. Nakaew N, Sungthong R, Yokota A, Lumyong S: Nonomuraea monospora sp. nov., an antimicrobial and anticancer compound-producing actinomycete isolated from Thai cave soil and emended description of the genus Nonomuraea. Int J Syst Evol Microbio/ 2012, aa:aa. doi:10.1099/ ijs.0.035220-0.

35. Ara I, Kudo T, Matsumoto A, Takahashi Y, Omura S: Nonomuraea maheshkhaliensis sp. nov., a novel actinomycete isolated from mangrove rhizosphere mud. J Gen Appl Microbiol 2007, 53:159-166.

36. Guan T-W, Wu N, Xia ZF, Ruan J-S, Zhang X-P, Huang Y, Zhang LL: Saccharopolyspora lacisalsi sp. nov., a novel halophilic actinomycete isolated from a salt lake in Xinjiang, China. Extremophiles 2011, 15:373-378

37. Al-Tai AM, Ruan J-S: Nocardiopsis halophila sp. nov., a new halophilic actinomycete isolated from soil. Int J Syst Bacteriol 1994, 44:474-478.

38. Jackson ML: Soil chemical analysis. New Delhi: Prentice Hall of India Private Limited; 1973:498.

39. Walkley A, Black JA: An estimation of digestion method for determining soil organic matter and a proposed modification of chromic acid titration method. Soil Sci 1934, 37:29-38.

40. Pamberton H: Estimation of total phosphorus. J Amer Chem Soc 1945 15:383-395

41. Mincer TJ, Jensen PR, Kauffman CA, Fenical W: Widespread and persistent populations of a major new marine actinomycete taxon in ocean sediments. Appl Environ Microbiol 2002, 68:5005-5011.

42. Mackay SJ: Improved enumeration of Streptomyces spp. on a starch casein salt medium. App/ Environ Microbiol 1977, 33:227-230.

43. Hopwood DA, Bibb MJ, Chater KF, Kieser T, Bruton CJ, Kieser HM, Lydiate DJ, Smith CP, Ward JM, Schrempf H: Genetic Manipulation of Streptomyces: A Laboratory Manual. Norwich: John Innes Foundation; 1985.

44. Lane DJ: 6S/23S rRNA sequencing. In Nucleic Acid Techniques in Bacterial Systematics. Edited by Stackebrandt E, Goodfellow M. New York: John Wiley \& Sons; 1991:115-175.

45. Rohlf FJ: NTSYS-pc numerical taxonomy and multivariate analysis system. New York: Exeter Publications Setauket; 1998. Version 2.02.

46. Jaccard P: The distribution of the Flora in the Alpine Zone. New Phytologist 1912, 11:37-50.

47. Nei M, Li WH: Mathematical model for studying genetic variation in terms of restriction endonucleases. Proc Natl Acad Sci U S A 1979, 76:5269-5273

48. Hall TA: BioEdit: a user-friendly biological sequence alignment editor and analysis program for Windows 95/98/NT. Nucleic Acids Symp Ser 1999, 41:95-98.

49. Altschul SF, Madden TL, Schaffer AA, Zhang J, Zhang Z, Miller W, Lipman DJ: Gapped BLAST and PSI-BLAST: a new generation of protein database search programs. Nucleic Acids Res 1997, 25:3389-3402.

50. Thompson JD, Gibson TJ, Plewniak F, Jeanmougin F, Higgins DG: The CLUSTAL-X Windows interface: flexible strategies for multiple sequence alignment aided by quality analysis tools. Nucleic Acids Res 1997, 25:4876-4882.

51. Felsenstein J: PHYLIP (Phylogeny Inference Package) version 3.68. Department of Genome Sciences. Seattle: University of Washington; 2008.

\section{doi:10.1186/2046-9063-8-23}

Cite this article as: Jose and Jebakumar: Phylogenetic diversity of actinomycetes cultured from coastal multipond solar saltern in Tuticorin, India. Aquatic Biosystems 2012 8:23. 